\title{
Cultura escolar en zonas de conflicto armado: del ámbito individual al trabajo colaborativo*
}

\section{School Culture in Armed Conflict Areas: From individual Domain to Collaborative Work}

\section{Cultura escolar em áreas de conflito armado: do ámbito individual ao trabalho colaborativo}

\author{
José Federico Agudelo-Torres** (iD) orcid.org/0000-0003-0916-7707 \\ Sandra Juliet Clavijo-Zapata*** iD orcid.org/0000-0003-2211-8897 \\ Marlon Vanegas-Rojas**** iD orcid.org/0000-0001-8846-0543
}

Para citar este artículo

Agudelo-Torres, J., Clavijo-Zapata, S. J. y Vanegas-Rojas, M. (2022). Cultura escolar en zonas de conflicto armado: del ámbito individual al trabajo colaborativo. Revista Colombiana de Educación, 1(84), 1-12. https://doi.org/10.17227/rce.num84-11318.

Fecha de recepción: 17/02/2020

* Este texto es derivado del proyecto de investigación: “Cultura escolar, profesionalidad pedagógica y trayectos biográfico-profesionales: un estudio cualitativo en las nueve subregiones de Antioquia", ejecutado durante el periodo 2018-2019 por el Centro de Pensamiento Pedagógico y patrocinado por la Gobernación de Antioquia.

\footnotetext{
** Docente Facultad de Educación y Humanidades. Universidad Católica Luis Amigó, Medellín, Colombia. Correo: federico.agudelo@udea.edu.co

*** Magíster en Desarrollo Infantil. Directora de la Licenciatura en Educación Infantil de la Universidad Católica Luis Amigó, Medellín, Colombia. Correo: dir.educacioninfantil@amigo.edu.co

**** Magíster en Educación. Docente de la Facultad de Educación y Humanidades, Universidad Católica Luis Amigó Medellín, Colombia. marlon.vanegasro@amigo.edu.co.
} 


\section{Resumen}

Palabras clave: educación; escuela; investigación

narrativa; maestro

Keywords: school; education; teacher; narrative research

Palavras-chave: educação; escola; pesquisa narrativa; professor
El presente artículo pretende reconocer la cultura profesional pedagógica de los maestros que habitan zonas de conflicto armado, a partir de relatos de experiencia; particularmente hacemos alusión a los que desempeñan su labor en la subregión del Bajo Cauca antiqueño. Para lograr el objetivo propuesto, se diseñó una investigación de corte cualitativo, enmarcada en una perspectiva biográfica narrativa. A su vez, y en procura de reconstruir la información generada, se elaboró una matriz de análisis, en la cual se advirtieron aquellos asuntos que, por su presencia y relevancia en las voces de los participantes de la investigación, se configuraron en ejes temáticos y categorías emergentes. Entre los hallazgos más significativos se ubican tres asuntos, a saber: las estrechas relaciones que se tejen entre el ejercicio profesional del maestro, las realidades cercanas al miedo y la zozobra en las que se circunscribe la vida en la escuela misma; la necesidad de favorecer el tránsito de una cultura escolar individualista a una cultura escolar colaborativa; y finalmente, la importancia de hacer de la escuela un escenario que forme a todos los sujetos en ella inmersos, en posturas resilientes.

\section{Abstract}

Based on the implementation of lived experience narratives, this article intends to recognize the professional and pedagogical cultures of those teachers who live in distant regions affected by the armed conflict. For that reason, a qualitative research project was conducted following a biographical narrative perspective. As to reconstruct the information generated, an analysis matrix was designed to identify recurrent and relevant issues emerging from the participants' voices. These issues became thematic axes and emergent categories. Concerning the findings, three major significant topics were identified, that is, the close relationships between teachers' professional exercise and their school realities of fear and anxiety, the necessity to nurture the collaborative cultures, and the importance of transforming the school into a suitable scenario for resilient identities

\section{Resumo}

Este artigo pretende reconhecer a cultura pedagógica profissional dos professores que vivem em áreas do conflito armado, a partir de relatos da sua experiência; em particular, referimo-nos àqueles que desenvolvem o seu trabalho na sub-região do Bajo Cauca antioqueño. Para alcançar o objetivo proposto, foi elaborada uma pesquisa qualitativa, enquadrada em uma perspectiva biográfica narrativa. Por sua vez, e na tentativa de reconstruir as informações geradas, foi elaborada uma matriz de análise, na qual se constataram aquelas questões que, por sua presença e relevância nas vozes dos participantes da pesquisa, se configuraram em eixos temáticos e categorias emergentes. Entre os achados mais significativos estão três questões, a saber: as relações estreitas que se tecem entre a prática profissional do professor e as realidades próximas ao medo e à ansiedade em que a vida se circunscreve na própria escola, a necessidade de favorecer a transição de uma cultura escolar individualista para uma cultura escolar colaborativa; por fim, a importância de fazer da escola um ambiente que forme todos os sujeitos nela imersos, em posturas resilientes. 


\section{Introducción}

Históricamente, a la institución escolar, entre otras tantas, le ha sido asignada la loable labor de formar. Verbo que nos remite, ineludiblemente, a un centenar de interrogantes, de los cuales y en procura de mantener cercanía con el objeto de esta investigación, destacaremos dos: ¿Qué tipo de hombre nos interesa formar? (Flórez, 2005), y ¿qué enseñar, qué historias reivindicar en el aula de clase? (Terrén, 1999). Con respeto al primero, las respuestas estarán ancladas a diversos discursos pedagógicos, soportadas en determinadas estructuras psicológicas y servirán, seguramente, en la construcción del modelo de sujeto que resulta paradigmático y necesario a una sociedad en particular. En el caso concreto de un territorio en permanente conflicto armado, y cuyos indicadores de violencia y muerte visitan de manera frecuente a la comunidad escolar, resulta menester repensar dicho interrogante. Así, a las clásicas teleologías escolares -es decir, a aquellas que hablan de la importancia de acceder a altos niveles de autonomía y a la consecución de la soberanía sobre sí mismo-, bien se les podría unir la experiencia, viva y vital, de los maestros de dichas zonas, quienes en su propia voz afirman que "lo más importante para heredar en estas regiones es la capacidad que han de poseer los educandos para sobrevivir en medio de tanta hostilidad" (Participante 4, Bajo Cauca antioqueño). Recordemos que, al hacer alusión a la subregión del Bajo Cauca antioqueño, hacemos referencia a la zona geográfica ubicada en el norte del departamento de Antioquia y en la cual se ubican los municipios de Caucasia, Tarazá, Puerto Valdivia y Cáceres entre otros.

Frente a la segunda cuestión, es menester indicar que la voz y el sentir de los maestros trascienden los currículos oficiales, por cuanto exhortan a sus educandos a cultivar y a cultivarse en aquel ejercicio en el cual la memoria no solamente es un lugar para recordar, sino una posibilidad para no repetir, para recomenzar de manera diferente. En este sentido, la concepción de memoria resulta cercana y próxima a la enunciada por Arias Gómez (2018), quien afirma que es menester hacer de la enseñanza de la historia del conflicto armado en la escuela una oportunidad para el nunca más de la repetición de este. A su vez, la concepción de olvido, como un importante objeto de reflexión, exhorta a todos los miembros de la comunidad educativa a pensar, no en aquella ausencia de palabra o de recuerdo, sino más bien en aquellos ámbitos cercanos a la reconciliación y al perdón. En el caso particular de la escuela colombiana, la Ley 1732 de 2014, por medio de la cual se instituye la Cátedra de la Paz en todas las instituciones educativas, se invita a pensar en un olvido lleno de asuntos por decir, de palabras por escuchar y de espacios y territorios para recuperar. En este sentido, y desde el cultivo de humanidad que se hace en la escuela que se encuentra circunscrita en ámbitos de intimidación y crimen, los maestros afirman en tono vehemente: "un estudiante que logremos quitarle a la calle y a la violencia es una buena noticia para la región" (Participante 1, Bajo Cauca antioqueño).

La cultura escolar, entendida como aquellas prácticas sociales y culturales en las que se enmarca el quehacer cotidiano del maestro y el despliegue mismo de la escuela como institución formadora, se torna en asunto móvil y movilizador, cuando dichas prácticas se ejercen en zonas de conflicto armado. En este sentido, González (1999) convoca a resemantizar asuntos como el lenguaje que emplea el maestro en el interior del aula, las relaciones que se tejen entre los padres de familia y la escuela, los ejercicios cercanos a las sanciones y las recompensas, así como el andamiaje mismo que le confiere al maestro el poder de enseñar algo. En este sentido, las diversas concepciones de cultura escolar que posee 
el maestro se ven interceptadas y transformadas por elementos circundantes al mundo de la escuela. Así, las cosmovisiones, las creencias y las experiencias culturales, hijas del conflicto armado, se tornan en huéspedes del quehacer mismo de la escuela.

Hargreaves (1996) hace alusión a cuatro tipologías de cultura escolar: individualista, colegiada artificiosa, balcanizada y colaborativa. Estas permiten la fusión entre ellas y la emergencia, como consecuencia lógica, de otras tipologías combinatorias. La primera hace referencia a todas aquellas prácticas escolares en las cuales el maestro trabaja de manera independiente, generando a su vez entornos escolares lejanos al trabajo colaborativo y distantes a la posibilidad de reconocer otredades. La segunda tipología hace alusión al trabajo en equipo que está mediatizado no por el deseo de trabajar unidos, sino por la necesidad o el requerimiento que la situación demande; sin duda, este resulta ser un ejercicio de alta regularidad en los ámbitos escolares. En tercer lugar, tenemos un modelo de cultura escolar caracterizado por la actividad aislada que realizan pequeños subgrupos de trabajo; es similar a pensar en microestructuras que cumplen con las finalidades planteadas, pero no se vinculan intencionadamente con la macroestructura. El último modelo hace referencia a la cultura escolar en la cual el trabajo colaborativo está enraizado en prácticas pedagógicas que, de manera premeditada, logran democratizar la labor docente y la consecución de sus propios fines.

Las categorías propuestas por el propio Hargreaves (1996) se quedan cortas frente a todas aquellas realidades que se pueden experimentar en las escuelas ubicadas, colindantes y circunscritas en zonas de violencia. En este sentido, Ramírez y Jiménez (2016) recuerdan que toda cultura conlleva un proceso de aprendizaje que está transversalizado por elementos como los hábitos, los valores y las conductas que emanan de las complejas relaciones establecidas entre los sujetos con el medio, y de este último con las instituciones. En este sentido, muchas de las relaciones que establece el maestro con su medio y con la institucionalidad que lo contienen están mediadas por afectos cercanos al miedo y a la zozobra; incluso uno de los participantes de la investigación decía: "estamos siempre a la espera de malas noticias, en procura de sabernos aún más solos" (Participante 7, Bajo Cauca antioqueño).

Ciertamente, no existe un currículo que forme al maestro para habitar escenarios de temor y nerviosismo, tampoco se advierten estructuras curriculares que le preparen a enfrentar procesos formativos en medio de la catástrofe; aun así, a la manera expresada por Ricoeur (2003), la acción de superar la linealidad del tiempo cronológico le permite a los maestros reconstruir, constantemente, aquella identidad que emana y se va configurando en ese nuevo tiempo en el que se ubican sus fisurados relatos y sus móviles historias. De esta manera, el quehacer del maestro y de la escuela se van imbricando, poco a poco, con el mundo de la vida que se gesta en esos territorios, siendo precisamente esa acción de tejido la que paulatinamente reconfigura la cultura escolar. Así, la concepción del currículo, planteada en el artículo 76 de la Ley General de Educación de 1994, y en la cual se hace alusión directa a la importancia de poseer criterios, planes, metodologías y procesos que ayuden a formar en una identidad local, regional y nacional, se ve desbordada por una realidad compleja, móvil y volátil.

Vivir, experimentar y fluir en una territorialidad que ha sido cultivada por la violencia, le significa al maestro aprender a moverse en escenarios cuyos relatos y narraciones le exhortan a reinterpretar, por cuanto él mismo se reinterpreta, su quehacer pedagógico y su propia función social. Así, la experiencia de la cultura escolar es también la experiencia de aquellas narrativas que no son sino en la fantasía y el anhelo. En este sentido, Connelly y Clandinin 
(1990) rememoran aquella virtud que posee el sujeto, cuando es capaz de narrar un lugar que experimenta únicamente en su propia narración, sabiendo que su relato es siempre un fruto colectivo. De igual forma, McEwan y Egan (2005) plantean que el uso de la narrativa aporta en la comprensión acerca de cómo se hacen y se piensan las prácticas pedagógicas y, con ello, cómo propende por su transformación. Así, la narración y el relato de los maestros que habitan zonas de conflicto armado se convierten en un importante insumo para pensar y resignificar la cultura escolar, en estas lógicas uno de los docentes afirmaba: "se hace necesario que nuestras voces y nuestros clamores superen el ámbito del aula e inicien un recorrido por toda la cultura" (Participante 9, Bajo Cauca antioqueño).

\section{Metodología}

Para la realización del presente artículo se planteó una investigación enmarcada en el paradigma cualitativo que, como lo enuncia Niño (2011), permite comprender de manera holística las problemáticas y los contornos en los que se ubican los determinados objetos de apetencia epistémica. A su vez, se trabajó desde un enfoque biográfico-narrativo, lo que permitió a los investigadores acceder de manera directa a las voces, los sentires y las interpretaciones de los sujetos convocados a la investigación misma.

Durante el proceso de recolección de información, se optó por la implementación de tres estrategias básicas, a saber: producción de narrativas, de carácter biográfico y realizadas por cada uno de los sujetos convocados a la investigación, elaboración de cartografías sociales, trabajadas en subgrupos bajo el criterio de ubicación geográfica y por último la realización de un ejercicio foto-narrativo. Es pertinente, en este punto, recordar que la población partícipe del proyecto estuvo constituida por aproximadamente treinta maestros y directivos docentes de la subregión del Bajo Cauca antioqueño, territorio ubicado geográficamente en el nororiente del departamento de Antioquia y poseedor de un triste y lamentable historial de más de cincuenta años de violencia.

Posterior a la implementación de las estrategias empleadas, se construyó una matriz de análisis categorial, se ubicaron y organizaron en ella aquellos asuntos de marcada relevancia para luego, a través de procesos de análisis y abstracción, acceder a triangular y a reinterpretar las relaciones halladas entre los diferentes registros. Resulta además importante hacer alusión al manejo ético de la información y a la administración respetuosa del material obtenido.

\section{Narrar en tiempos de crisis: de lo contingente a lo posible}

El hombre, en términos de Mélich (2010), es un homo narrans; es decir, el sujeto es un contador de historias. Se comparten aquellos relatos que amplían los horizontes con los cuales se ve y se piensa el mundo que se cuenta, pero también se narran aquellos asuntos que rememoran las dificultades económicas, políticas, sociales y culturales que habitan el mundo en el que se reside y del cual, ineludiblemente, se es coconstructor.

La idea de cómo se interioriza el mundo es, sin duda, cercana y próxima a la idea de cómo se narra ese mundo que se interioriza. Así, los relatos trascienden lo individual y se acercan e imbrican con esferas sociales y culturales. Bien se haría entonces en afirmar que toda narrativa es una posibilidad emergente para conocer el mundo. Afirmemos que, al igual que las sociedades, la escuela se ha erigido con base a un sinnúmero de relatos en los que se 
manifiestan los temores, los anhelos, las identidades, las profundas cargas subjetivas y los deseos por decir una palabra; narrar la escuela en medio del conflicto armado es convocar a los protagonistas a decir, en tanto ellos mismos se dicen, nuevas palabras.

Difícilmente podría existir una narrativa exclusiva para tiempos felices, penosamente existiría una franquicia para relatar tiempos violentos; así, entre los buenos tiempos y los no tan agradables, se despliegan los relatos y las narrativas de aquellos que habitan un tiempo y un espacio determinado. Decir lo contingente y lo azaroso se torna en una aventura por decir lo posible y lo tangible. En este sentido, Nussbaum (1995) recuerda que aquellas situaciones relacionadas con la fortuna y la contingencia afectan la vida de los sujetos, pero también modifica en gran medida su sistema de valores. El quehacer de la escuela en zonas de conflicto armado no es ajeno a estos elementos, incluso los maestros sostienen que "en estos territorios hay que estar preparados para ir a una fiesta o a un funeral, en cualquier momento ocurren cosas" (Participante 4, Bajo Cauca antioqueño).

En este sentido, la narrativa es, además de una metódica de investigación, una posibilidad ontológica por saber al sujeto que se sabe en comunidad, por lograr interpretar sus palabras y esperar descifrar sus silencios y afonías. La escuela además de narrar sus currículos oficiales relata aquellos asuntos que la sujetan al mundo de la vida, no se trata de reducir la comprensión que se tenga de una cultura a las narraciones que de ella emerjan, sino más bien de advertir en dichas narraciones la continuidad y la movilidad que le es consustancial a la cultura misma. En la narración se puede leer la fortuna y la contingencia, expresadas en las propias voces de quienes realizan el ejercicio narrativo. En este sentido, la narrativa de los maestros, como ejercicio de exégesis e interpretación del mundo de la vida, reconfigura paulatinamente la cultura escolar de aquellas zonas de conflicto. El cuestionamiento por cómo se narra lo que se narra posee una semántica distinta en estas zonas, así uno de los maestros nos refería: "algunas veces no se sabe si es más tenebroso contar las cosas que suceden o contar dichos acontecimientos en un tono de voz determinado. Finalmente, lo importante es contar las cosas" (Participante 3, Bajo Cauca antioqueño).

Saber y reconocerse contingente es la exhortación a narrar la vida como un hecho inestable, móvil y movedizo; es la oportunidad para cambiar cuando todo cambia; es la alternancia entre los deseos y los temores; es una eventualidad de hacer posible aquello que hasta ahora no lo es. Estar al tanto de narrar la contingencia que habita la escuela también es la emergencia que posibilita el cambio de la misma. Así, reconocer la violencia que en ella se desenvuelve es la génesis para que el maestro transforme y resignifique su propio ser y su auténtico estar allí. Transitar de lo contingente a lo posible es una de las más hermosas teleologías de la voz y del saber del maestro. Bruner (2003) sostuvo, en su momento, que el ejercicio narrativo propende por ponerle ropaje a los sentires y a las interpretaciones, de ahí que no resulte descabellado afirmar que el hábito del maestro por narrar en tiempos de crisis le permita reinterpretar, en tanto se reinterpreta, una y mil veces su propio quehacer en la cultura escolar.

\section{De la cultura individual al cultivo de lo colaborativo}

En la cotidianidad de la escuela se establecen diálogos, conversaciones entre extraños que incluso pueden terminar siendo cómplices, en la escuela se habla con otros que constituyen esa alteridad con la cual se de-construye la propia mismidad del sujeto. Transitar de lo individual a lo colaborativo en el mundo de la escuela se constituye en uno de los mayores 
gestos de toda narrativa. Son los relatos y las apuestas formativas que en ellos habitan los que logran amalgamar la vida que transcurre en la escuela. En este sentido, Skliar (2017) plantea que el gesto de educar es

Escuchar y contar nuestras historias, cualesquiera que sean ellas, con las palabras que sean, pero nuestras, para dar paso a la alteridad. Y esa alteridad sobre puede sobrevenir bajo cierta forma de conversación, que nada tiene que ver con la hipocresía ni con la arrogancia del dar voz a los que creemos que no la tienen. (p. 16)

Así, bien se podría afirmar que la práctica narrativa es una filiación del sujeto individual que procura por la emergencia de una cultura colaborativa, hay en la narración del sujeto una intrínseca finalidad por crear comunidad. De ahí que los maestros que formaron parte de la presente investigación afirmaran en varias ocasiones, fehacientemente que

dar a conocer aquellos asuntos que ocurren en una comunidad en medio de la violencia se torna en una importante oportunidad para generar sensibilidad y con-misericordia entre aquellos que se creen lejanos y en cambio resultan estar muy cerca, pues comparten el mismo espacio vital (Participante 3, Bajo Cauca antioqueño)

En estas mismas lógicas, la estrategia de compartir una memoria colectiva, de reinterpretar de manera grupal lo que acaece con uno de los miembros de la comunidad y el anhelo por mantener viva la memoria, se ha convertido en un puente que le permite a la individualidad del sujeto cruzar y empalmarse con la colectividad del grupo. Así, a la manera expuesta por Linares y Galeano (2015), resulta vital repensar el papel de la memoria y el rol del olvido, en procura de mantener vigente una cultura próxima a lo colaborativo y a través de ella, acercarse a prácticas de paz y reconciliación. Ejercicio que habrá de realizarse desde el complejo escenario escolar.

La oportunidad del sujeto por reconocerse, en tanto reconoce la voz que emana de su alteridad, le permite establecer una valiosa relación tripartita, la cual evidencia la corresponsabilidad y la dependencia que existe entre la mismidad que le constituye y la interpelación que existe entre el mundo de los otros y aquello otro que constituye el mundo mismo. Ricoeur (1999) enuncia este fenómeno como la posibilidad que tiene el sujeto de saberse intérprete de sí mismo, del otro y del mundo, a través del acto narrativo. En referencia a esta postura, uno de los directivos docentes afirmaba: "es mediante la escucha, auténtica y fidedigna, de las palabras que procuran aquellos que han vivido la tragedia del conflicto armado, que el sujeto logra saberse parte e incluso protagonista de la tragedia" (Participante 3, Bajo Cauca antioqueño).

Y es precisamente la presencia de esa tríada -a saber: el sujeto que se sabe intérprete e interpreta el mundo y la alteridad del mundo mismo- lo que hace que se pueda transitar del trabajo individual al trabajo colaborativo. Una cultura escolar que se sepa a sí misma colaborativa será un escenario óptimo para la emergencia y la cocreación de discursos, actividades y sentires que contrarresten los efectos del conflicto armado. Siendo entonces sabedor de que la condición humana es siempre susceptible de ser narrada, el maestro que labora en dichos territorios habrá de convertirse en un incansable relator de oportunidades, de aquellas que son porque ya acaecieron y de aquellas otras que no han ocurrido, pero son en el mundo de la esperanza que existe en cada uno de los sujetos que cohabitan aquellos espacios. Con ello resulta claro que toda narrativa tiene la virtud de construir la experiencia humana, pero también resulta evidente la posibilidad de reconstruir dichas experiencias a 
través de nuevas narrativas, convirtiéndose estas últimas en reto y oportunidad de tránsito hacia una cultura colaborativa.

En este sentido, Álvarez y Marrugo (2016) plantean que una determinada cultura en la escuela no se cambia con un decreto, una normativa o una nueva legislación; en cambio, sostienen que una cultura escolar se modifica con el trabajo mancomunado de todos los agentes que en ella intervienen, incluido, obviamente, el quehacer de las posturas del Estado y, por ende, las del gobierno de turno. De igual manera, Jiménez et al. (2010) exhortan a trabajar desde el interior de las aulas en la formación de competencias ciudadanas, no como meros requerimientos oficiales, sino como estrategias que ayuden a repensar la convivencia en la escuela. A estas aseveraciones uno de los docentes de invitados a la investigación decía: "vemos cómo los representantes del gobierno llegan a estas zonas a exponer grandes ideas... pero no se quedan para operativizarlas, es como si ellos fuesen la teoría y nosotros la práctica" (Participante 11, Bajo Cauca antioqueño).

Una apuesta distinta plantean Ramírez y Jiménez (2016), quienes enfatizan en la importancia de repensar la civilidad, como estrategia y método en procura de contrarrestar los efectos de la violencia en las escuelas ubicadas en zonas de conflicto armado. Esta idea pareciera ser bien acogida por los maestros que trabajan en dichos escenarios y coinciden en la importancia de resemantizar el rol de la civilidad en las prácticas cotidianas que se generan en la escuela. De ahí que uno de los directivos docentes afirmara: "reconquistar el valor de la civilidad y el rol del sujeto como ser político, haría de la cultura escolar existente, un escenario propicio para la vida y el cultivo de nuevas prácticas escolares" (Participante 14, Bajo Cauca antioqueño).

\section{Del miedo a la resiliencia}

La capacidad de narrar y narrarse del sujeto resulta contraria, metafóricamente hablando, a su enmudecimiento; de ahí que narrar sea una práctica exegética y de introyección del propio sujeto que relata. Así, resulta menester plantear los siguientes interrogantes: ¿Cómo narramos lo que narramos? ¿Cómo narramos lo que narramos cuando somos protagonistas? ¿Cómo narramos lo que narramos cuando somos testigos? Estos tres cuestionamientos, aparentemente distintos, poseen una enorme similitud, a saber: aclaran que toda narrativa existe por cuanto relata experiencias que vinculan al sujeto con su otredad, con su herencia, con su accionar humano. No existe una narrativa en soledad, pues el narrador nunca narra su experiencia aislada, él es un relator de muchas vidas; pues en sus historias se cuentan y se imbrican muchas otras existencias, cada una de ellas relatadas en tiempos heterogéneos. Según Agudelo (2016),

El que narra deja de ser un simple testigo y en cambio se transforma en protagonista del saber mismo, de igual manera aquel que escucha; a diferencia de lo que pensó la escuela tradicional, no permanece inmóvil pues adopta diversas posturas frente al discurso. Así, nos resulta claro comprender que entre aquel que presta su voz y aquellos que ofertan su oído, existen y emergen múltiples e infinitas posibilidades. (p. 10)

Transitar de una cultura del miedo a una cultura de la resiliencia se hace evidente en muchas de las narraciones de los maestros vinculados a zonas de conflictos. En sus relatos se atisba que la narración es también esperanza, pues en ella también se dice el mundo que no es por fuera de la escuela, pero cuya existencia resulta ser anhelo irredento del sujeto que se 
narra desde la escuela misma. Movilizar al sujeto de estadios de miedo a estadios de resiliencia recuerda, a la manera expresada por Santos Guerra (2007), que el afecto que emana de las historias que se cuentan en la escuela, resultan tener un efecto multidimensional, pues tienen que ver con todo y con todos.

Desde esta perspectiva, Lizarralde (2003) sostiene que "el miedo sin embargo no es de por sí un sentimiento negativo, sino que como valor adaptativo tiene un carácter positivo al ayudar a los sujetos a percibir el riesgo y de esta manera posibilita la sobrevivencia" (p. 3). Respecto a esta interesante postura, los maestros vinculados a la investigación sostuvieron: "es muy importante que nuestros estudiantes sepan que muchas de las historias que contamos no son para generar miedo, sino para invitarlos a ser valientes" (Participante 5, Bajo Cauca antioqueño).

El devenir de la tragedia que surge en la cotidianidad del conflicto posee, irónicamente, un alto sentido pedagógico. El ejercicio de narrar ciertos asuntos, con el ánimo de que estos no vuelvan a suceder; permite apreciar la capacidad didáctica de las vicisitudes humanas. Bruner (1998) recuerda la enorme dignidad que habita en el relatar no solamente la fortuna, sino también la contingencia humana. Así, la narración que crece a la sombra del miedo puede convertirse intencionada e intencionalmente en la génesis de estados superiores.

Emplear la memoria como estrategia de no repetición y el olvido como elemento fluctuante de cambio genera en el maestro que narra una neófita oportunidad de tránsito y transformación. Así, el proceso hermenéutico de muchas narrativas forjadas en la cultura del miedo tiene la posibilidad de transformarse en relatos resilientes. En este contexto, Contreras y Pérez (2010, citado por Landin y Sánchez, 2019) sostienen que abrirse al encuentro del otro, a su comprensión, ocurre en el seno de la relación, en el intento de reconocimiento y aceptación, así como de desencuentro, miedo y conflicto.

Es imposible la generación de estados resilientes, sin la presencia de lo trágico y lo contingente. De ahí que muchas veces las malas noticias que rondan los escenarios educativos que se ubican en medio del conflicto armado se tornen en dignos objetos de reflexión pedagógica; con la finalidad de formar un sujeto más valiente, preocupado por el cuidado de sí, de sus otredades y del entorno. Incluso, uno de los directivos docentes clamó: "la paz que tanto deseamos en este territorio tendrá que ser cosechada por una escuela que se niegue a sucumbir a la violencia y a los violentos" (Participante 10, Bajo Cauca antioqueño).

De ahí que resulte importante pensar la idea sostenida por Méndez (2014), al plantear la necesidad de realizar un análisis integral de la problemática de la formación escolar en zonas de conflicto armado; pues es menester mantener abierto el campo de lo posible, todo ello en procura de superar la homogenización en los procesos formativos y adentrarse en la integralidad que le habrá de resultar consustancial a la escuela misma.

Es importante señalar en este punto la valentía y el coraje de algunos maestros por generar nuevas narraciones de lo acaecido, en tanto exhortan a pensar en la necesidad de relatar otros asuntos, incluso una de las maestras afirmaba: "es de vital importancia que los docentes de estas regiones aprendamos a contar lo bueno, a relatar las historias positivas y a esperar, pacientemente, que estas también se conviertan en referentes del y para el territorio" (Participante 12, Bajo Cauca antioqueño). Respecto a este enunciado, Polkinghorne (1995) recuerda que las descripciones narrativas muestran que la actividad humana es siempre una implicación en el mundo con un propósito determinado; así, los tránsitos del miedo 
engendrado en el mundo del conflicto armado, a los escenarios de paz y convivencia que denota la escuela, necesita de maestros resilientes y cercanos al reto de narrar nuevas historias, relatos en los que la visión de ciudadanía y participación política, a la manera expresada por Avendaño et al. (2016), permita a los habitantes de zonas en conflictos saberse artífices y protagonistas de su ser y su habitar en dicho espacio.

\section{Conclusiones}

Reconocer la cultura escolar como aquel conjunto de prácticas, hábitos, costumbres y cosmologías que emergen, se diseñan y se coconstruyen en el quehacer cotidiano de la escuela; es también reconocer que las vicisitudes del mundo de la vida afectan en gran medida aquellas construcciones institucionales. La figura y el quehacer del maestro no son ajenos a dichas volatilidades; en cambio, resultan transfigurados por dichos asuntos; máxime si estos se enmarcan en zonas de conflicto armado.

El miedo, la zozobra y el temor constante por lo que pueda acaecer en la escuela y en los territorios en las que ella se ubica hacen que la labor del maestro se transforme y devenga en otros múltiples asuntos. Así, las preguntas normativas esbozadas por cualquier currículo, qué enseñar, cómo enseñar, para qué enseñar...- se ven reemplazadas, en muchas oportunidades, por narrativas que cuentan historias de supervivencia y desplazamiento; pero también por relatos que evidencian la tenacidad de nuevas oportunidades y la puesta a punto de circunstancias que hacen brotar la resiliencia y la capacidad transformadora del maestro y de la escuela. En este sentido, muchos de los relatos que emergen de la tragedia y el conflicto armado han sido resignificados por los educadores, haciendo de ellos una estrategia pedagógica que logra subsanar las esferas del miedo, en tanto que se configuran en ejercicios de resiliencia y valor.

A su vez, resulta importante señalar que el tránsito de una cultura individualizada a una cultura colaborativa, en la escuela ubicada en zonas de conflicto armado, se configura en la relación multidimensional que estable la escuela con el mundo de la vida que la rodea y la circunscribe. Así, por ejemplo, el trabajo mancomunado entre el maestro y la familia, entre los docentes de las zonas rurales y los de las zonas urbanas, así como el compartir de aquellos asuntos que le son cotidianos a la escuela -un acto cívico, una feria de la ciencia, un festival de la canción, una salida pedagógica, un torneo intercolegiado, entre otros- han logrado transformar las narrativas y los relatos que emergen en estas zonas, con lo cual se potencian los tránsitos de las culturas individualizadas a las culturas colaborativas. 


\section{Referencias}

Agudelo Torres, J. F. (2016). El cuento como estrategia pedagógica: una apuesta para pensarse y narrar-se en el aula. Fondo Editorial Luis Amigó.

Arias Gómez, D. H. (2018). Abordajes escolares de la violencia política y el conflicto armado en Colombia. (Spanish). Educación y Ciudad, 34, 25-38. https://doi.org/10.36737/01230425.v0.n34.2018.1867

Álvarez, A. L. y Marrugo, P. A. (2016). Cátedra de la paz en Colombia: una mirada que supera la tiza y el tablero. Boletín Virtual, 5(9), 168-174.

Avendaño Castro, W. R., Paz Montes, L. S. y Parada-Trujillo, A. E. (2016). Construcción de ciudadanía: un modelo para su desarrollo en la escuela. Ágora U.S.B., 16(2), 479-492. http://www.scielo.org.co/scielo.php?script=sci_arttext\&pid=S1657-

$80312016000200007 \&$ lng =en\&tlng=

Bruner, J. (1998). Realidad mental y mundos posibles. Gedisa.

Bruner, J. (2003). La fábrica de historias: derecho, literatura, vida. Fondo de Cultura Económica.

Congreso de la República de Colombia. Ley 115 de 1994. Por la cual se expide la Ley General de Educación. http://www.secretariasenado.gov.co/senado/basedoc/ley_0115_1994.html

Congreso de la República de Colombia. Ley 1732 de 2014. Por la cual se establece la Cátedra de la Paz en todas las instituciones educativas del país. https://www.mineducacion.gov.co/1759/w3-article-381604.html?_noredirect=1

Connelly, M. y Clandinin, J. (1990). Stories of experience and narrative inquiry. Educational Researcher, 5(19), 2-14.

Contreras. J. y Pérez, N. (2010). La experiencia y la investigación educativa. En J. Contreras y N. Pérez (comps.), Investigar la experiencia educativa (pp. 21-86). Morata.

Flórez, R (2005). Pedagogía del conocimiento. McGraw-Hill.

González, L. (1999). Pueblo en vilo. Fondo de Cultura Económico.

Hargreaves, A. (1996). Profesorado, cultura y postmodernidad (Cambian los tiempos, cambian los profesores). Morata.

Jiménez, M., Lleras, J. y Nieto, A. (2010). La paz nace en las aulas: evaluación del programa de reducción de la violencia en Colombia. Educación y Educadores, 13(3), 347-359. http://educacionyeducadores.unisabana.edu.co/index.php/eye/article/view/1729/2331

Landín Miranda, M. del R. y Sánchez Trejo, S. I. (2019). El método biográfico-narrativo: una herramienta para la investigación educativa. Educación, 28(54), 227-242. https://dx.doi.org/10.18800/educacion.201901.011

Linares Alvarado, M. y Galeano Hernández, S. (2015). La universidad frente a la construcción de paz: claves para una convivencia posible y duradera. Revista Universidad de La Salle, (67), 95-105. https://revistas.lasalle.edu.co/index.php/ls/article/view/3626

Lizarralde, M. (2003), Maestros en zonas de conflicto. Revista Latinoamericana de Ciencias Sociales, Niñez y Juventud, 1(2), 2-25. 
McEwan, H. y Egan, K. (2005). La narrativa en la enseñanza el aprendizaje y la investigación. Amorrortu Editores.

Méndez Gómez, D. M. (2014). Desarrollo humano en la formación de formadores: una pedagogía para la paz, la reconciliación y la esperanza. Revista Universidad de La Salle, [S.I.](65), 149-161.

Mélich, J.C (2010). Ética de la compasión. Herder.

Niño, V. (2011). Metodología de la investigación. Ediciones de la U.

Nussbaum, M. (1995). La fragilidad del bien. Fortuna y ética en la tragedia y la filosofía griega. Editorial Visor.

Polkinghorne, D. (1995). Narrative configuration in qualitative analysis. En J. Hatch y R. Wisniewski (eds.), Life history and narrative (pp. 5-23). Falmer Press.

Ramírez Monsalve, E. y Jiménez Builes, J. A. (2016). Construcción de ciudadanías en sociedades con altos niveles de conflictividad y crisis a través de una iniciativa pedagógica. Ágora U.S.B., 16(2), http://www.scielo.org.co/scielo.php?script=sci_arttext\&pid=S1657$80312016000200013 \&$ lng =en\&tlng=es

Ricoeur, P. (1999). Historia y narratividad. Ediciones Paidós, ICE, Universidad Autónoma de Barcelona.

Ricoeur, P. (2003). Tiempo y narración III: el tiempo narrado. Siglo XXI Editores.

Santos Guerra, M. A. (2007) Arqueología de los sentimientos en la escuela. Bonum.

Skliar, C. (2017). Pedagogías de las diferencias. Graó.

Terrén, E. (1999). Educación y modernidad, entre la utopía y la burocracia. Anthropos. 